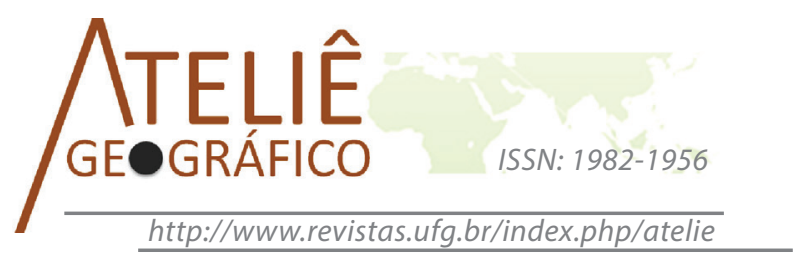

\title{
Do sertão ao cerrado: trajetórias do território e do sertanejo goiano
}

\author{
From the hinterland to the savannah: territorial and \\ hinterland trajectories in Goiás state, Brazil
}

\section{Del sertão al Cerrado: trajetorias del territorio y del sertanejo de Goiás}

\author{
Júlio César Pereira Borges \\ Universidade Estadual de Goiás - Câmpus Pires do Rio \\ jcesar.ueg@gmail.com
}

\begin{abstract}
Resumo
Com base na refuncionalização territorial de Goiás, este artigo busca analisar a inserção desse estado na lógica da expansão capitalista na América Latina e no Brasil, enfatizando como a vida sertaneja local é transformada pela ação do capital, responsável pela passagem de Goiás do sertão para Goiás do cerrado. É nessa perspectiva que está pautado este estudo, ou seja, no entendimento da interação dos elementos políticos, econômicos e culturais que se processam na inserção de Goiás na lógica da expansão capitalista e como essa situação ressoa na vida do sertanejo goiano. Para isso, realizou-se uma análise bibliográfica sobre a leitura geográfica do cerrado, acompanhada de entrevistas com pesquisadores do assunto. Tais ferramentas nos possibilitaram entender a incorporação do cerrado na dinâmica do capitalismo mundial e sua reverberação na (re)existência do sertanejo goiano.

Palavras-chave: Expansão Capitalista; Cerrado Brasileiro; Território Goiano; (Re)Existência Sertaneja.
\end{abstract}

\begin{abstract}
By introducing a debate grounded on the territorial refunctionalization of Goiás state, this article addresses the inclusion of Goiás within the logic of capitalist expansion in Brazil and in Latin America. Moreover, it stresses the way the sertanejo way of life is transformed by the role of capital, which is responsible for the transition from hinterland to savannah in Goiás. The present research stems from understanding the interaction between political, economic, and cultural elements processed in the inclusion of Goiás within the logic of capitalist expansion in Brazil, as well as the way this scenario resonates in the life of the state's hinterland. To achieve that, this paper brings forth a bibliographical survey of geographical research on the state's
\end{abstract}


savannah, as well as interviews with researchers. These tools made it possible to understand the savannah's incorporation into the dynamics of global capitalism and its reverberation in Goiás' hinterland (re)existence.

Keywords: Capitalist Expansion; Brazilian Savannah; Goiás' Territory; Hinterland (Re)Existence.

\begin{abstract}
Resumen
Con base en la refuncionalización territorial de Goiás, este artículo analiza la inserción de este estado em la lógica de la expansión del capitalismo en América Latina y en Brasil, enfatizando como la vida sertaneja local es transformada por la acción del capital, responsable po el paso de Goiás del sertão a Goiás del Cerrado. Es en esta perspectiva que está pautado este artículo, o sea, en el entendimiento de la interacción de los elementos políticos, económicos y culturales que se procesan em la inserción de Goiás en la lógica de la expansión capitalista y como esa situación resuena en la vida del sertanejo de Goiás. Por lo tanto, se realizo um análisis bibliográfico sobre la lectura geográfica del Cerrado, acompanhada de entrevistas con investigadores del asunto. Tales herramientas son indispensables para entender la incorporación del Cerrado em la dinâmica del capitalismo mundial y su reverberación en la (re) existencia del sertanejo goiano.

Palabras clave: Expansión capitalista; Cerrado brasileño; Territorio Goiano; (Re) existencia sertaneja.
\end{abstract}

\title{
Introdução
}

Na atualidade, é grande o número de pesquisas referentes ao cerrado brasileiro, as quais o transformam em um dos grandes lócus da curiosidade científica em nível nacional e internacional. Nesse bojo, a Geografia, mais precisamente a Geografia produzida em Goiás, ao acompanhar sua pluralidade, tem-lhe empregado variadas leituras.

Ao propor uma discussão sobre o cerrado goiano elencando a refuncionalização territorial de Goiás, este artigo busca analisar a inserção dessa unidade da federação na lógica da expansão capitalista na América Latina e no Brasil, enfatizando a ação dos sujeitos na transformação espacial de Goiás e a reverberação dessa ação na existência do sertanejo goiano. Nesse sentido, tem-se como prioridade compreender como a vida sertaneja é impactada pelo papel do capital no estado, responsável pela passagem de Goiás do sertão para Goiás do cerrado.

A ideia de sertão que aqui se discute vai além da visão política e econômica, abrangendo também a sua condição cultural. Por isso, o sertão goiano refere-se à realidade que, em virtude de sua função na divisão regional do trabalho entre os séculos XVIII e XX, condicionou a existência do sertanejo local. O sertão surge como lócus daqueles que viveram essa condição: o índio, o agregado, o chacareiro, o vaqueiro, o peão e todos os outros tipos que compuseram essa realidade.

O sertão como palco da existência sertaneja, sob os moldes da época, pautava-se na ruralidade, na quase completa sustentabilidade própria e no pouco contato externo. As necessidades básicas dos sertanejos eram supridas na propriedade rural por meio 
da produção diversificada, da criatividade ao desenvolver utensílios e instrumentos de sobrevivência na sua ligação intrínseca com a natureza. Entender o sertão goiano consiste, assim, em compreendê-lo como estrutura territorial do mundo sertanejo e como produto e produtor de uma sociabilidade comandada pela lógica do tempo lento e da acumulação simples, sob os preceitos da ruralidade.

Não se pretende, com isso, fazer uma leitura homogeneizante do sertão, muito menos do sertanejo. Em sintonia com Mendonça (2004), o sertão é pensado como construção social e histórica, valorizando-se e não negando-se as trajetórias preexistentes à modernização do campo em Goiás. Os conflitos de interesse e a luta de classes no sertão goiano - que, embora camuflados, eram manifestos - são considerados na presente análise.

No século XX, Goiás passa a ser estratégico para a interiorização do capital no Brasil, tornando-se um dos principais focos da intervenção capitalista. Essa situação rapidamente refuncionalizou sua estrutura territorial e, por consequência, o modo de vida do seu povo. É nessa perspectiva que está pautada esta pesquisa, isto é, no entendimento da interação dos elementos políticos, econômicos e culturais que se processam na inserção de Goiás no âmbito da lógica de apropriação do cerrado pela expansão capitalista no Brasil, e de que forma essa situação ressoa na vida do sertanejo goiano.

Esta pesquisa busca responder às seguintes questões: como se deu a inserção do cerrado na expansão capitalista pelo Brasil? Como Goiás está inserido nessa lógica? De que maneira essa condição impactou no modo de vida do sertanejo goiano? Para cumprir os objetivos propostos, realizou-se uma análise bibliográfica sobre a leitura geográfica do cerrado no território goiano, acompanhada de entrevistas com pesquisadores do assunto. Buscou-se uma fundamentação teórica e metodológica que possibilitasse compreender a incorporação do cerrado na dinâmica do capitalismo mundial, a inserção de Goiás nesse processo e o modo como essa condição determina a (re)existência do sertanejo goiano.

Entende-se que, ao responder às questões levantadas, desvenda-se a interação da existência sertaneja com o avanço do capital no cerrado e o modo como esse capital está atrelado ao movimento do mundo, que é dado pelo seu caminhar histórico. Entendese também que não há como escapar do jogo de relações entre o lugar e o mundo, em que se situam a singularidade, a totalidade e as mediações. Eis então a geograficidade da questão: a análise do território goiano pelo viés político, econômico e cultural, na interpretação das condições e da realidade da passagem de Goiás do sertão para Goiás do cerrado.

\section{O cerrado e a geografia feita em Goiás}

Pela via da Geografia, numa perspectiva biogeográfica, já se sabe das condições naturais do cerrado: lugar de rica biodiversidade, berço das águas e de extensos chapadões, clima bem definido (CUNHA, 2008; FERREIRA, 2008). Já se sabe também, por um viés político e econômico, da lógica da expansão capitalista, do papel estratégico do Estado - que é ideológico e de representação de classe - no direcionamento do capital no centro do território brasileiro (GOMES, 2008). 
É sabido também, como apontam Campos Filho (2010) e Inocêncio (2012), que há uma condição geopolítica na apropriação do cerrado pelo capital. Nesse processo, há acertos políticos entre órgãos locais, nacionais e internacionais, assim como entre empresas, empreendedores e proprietários que vão se beneficiar de suas estratégias, sob a lógica que Inocêncio (2012) considera como ação das redes de poder.

Sabe-se, ainda, que cada atividade produtiva ou processo que gera renda mediante o uso do território incide sobre o trabalho. Portanto, já se tem total certeza de que o processo de geração de alta rentabilidade pode criar grandes contradições sociais e regionais. Além do trabalho - ou juntamente com ele -, gostos, costumes, formas de morar, estilos de lazer, hábitos alimentares, relações afetivas e princípios morais participam das transformações na adequação forçada ao novo (CHAVEIRO, 2005).

Na perspectiva de Mendonça (2004), as pesquisas desenvolvidas no âmbito da ciência geográfica em Goiás também identificaram uma ação organizada, por parte dos povos do cerrado, de resistência ao abuso da rentabilidade acumulada do capital. Tal condição propiciou o fortalecimento de movimentos como o Movimento dos Atingidos por Barragens (MAB) e o Movimento dos Sem-Terra (MST), dentre outros do gênero, intensificando a disputa entre capital e trabalho.

Por meio dessa Geografia se levantou, se analisou e se compreendeu o modus vivendi das comunidades tradicionais ao estabelecer uma estreita intimidade com seus saberes, afazeres e ligação com o cerrado, o que é discutido por Almeida (2010), Chaveiro e Castilho (2007), Lima (2010) e Silva (2010). Os estudos atentaram-se, ainda, para o fato de que há grande interesse de corporações na apropriação dos saberes das comunidades do cerrado, como aponta Calaça (2010). Pela via da Geografia feita em Goiás, sabe-se que o cerrado é um território em disputa, fato evidenciado por Gomes (2008) e Pelá e Mendonça (2010).

Nos últimos anos, o uso da geotecnologia permitiu uma intensa e detalhada cartografia do cerrado, com ênfase na espacialização da ação antrópica. Ferramentas como imagens de satélites e veículos aéreos não tripulados (Vant), dentre outras, possibilitam o monitoramento do cerrado em tempo real, em que atividades como desmatamento, avanço da cana-de-açúcar e uso de recursos hídricos são acompanhadas dia a dia. Tal questão é discutida por Silva e Anjos (2010).

No bojo dessas discussões, as pesquisas geográficas apontam que a região do cerrado está entre as mais desenvolvidas economicamente. No entanto, e em razão desse desenvolvimento, como ela constitui um hotspot, para lembrar o conceito do ecólogo inglês Norman Myers criado em 1988. As pesquisas revelam também uma intensificação do índice de urbanização do cerrado, com destaque para o eixo Anápolis-Goiânia-Brasilia, bem como o aumento da violência, da pobreza e da segregação urbana (ARRAIS, 2013; TEIXEIRA NETO, 2008).

Essa é a dimensão das pesquisas de Geografia feitas em Goiás. Segundo Castilho e Chaveiro (2010), Chaveiro e Barreira (2010) e Calaça (2010), tais leituras ocorrem isoladamente e, por isso, não revelam o cerrado na íntegra. São pesquisas que ora o tratam como bioma, domínio morfoclimático, sistema biogeográfico e ecossistema, ora como 
região, patrimônio cultural, fronteira e território. Esse fato levou os autores mencionados a propor o estudo do cerrado via bioma-território, que implicaria na valorização de suas características naturais - via bioma - e dos aspectos econômicos e culturais - via território. Perfaz-se, assim, uma leitura integrada, à qual esta pesquisa buscou se filiar.

Diante do quadro apresentado, dois pontos são levantados. O primeiro diz respeito à contribuição da Geografia feita em Goiás para uma leitura da complexidade do cerrado que ultrapassa os aspectos naturais, destacando também as dimensões econômica, política e cultural que reverberam na perspectiva territorial. O segundo ponto refere-se aos limites dessas análises, uma vez que é impossível realizar uma leitura do cerrado que seja, de fato, integral. Qualquer leitura sobre o cerrado feita por meio de qualquer outra ciência é incompleta dada a limitação de qualquer campo do conhecimento. Um pesquisador de outra área irá lê-la e apontar falhas e lacunas, daí sua incompletude.

Na perspectiva desta pesquisa, a análise cobra a discussão de uma Geografia andante do capital no cerrado brasileiro com ênfase no território goiano, atentando para sua ação transformadora não só de lugares, mas, acima de tudo, da estrutura local. Junto a essa condição enfatizou-se sua reverberação na condição existencial do sujeito tradicional, aqui entendido como sertanejo goiano.

\section{Goiás: do sertão ao cerrado}

Oficialmente, já não há mais sertão em Goiás, embora possa ser reconhecida a presença de traços culturais sertanejos na identidade regional. [...] A desaparição do termo sertão como a imagem com a qual se identificava o Estado de Goiás foi diretamente proporcional à consolidação do termo cerrado como um dos símbolos estaduais.

Corbacho Quintela (2010, p. 242, grifo do autor)

As palavras de Corbacho Quintela (2010) são direcionadas por um estudo voltado para as investidas que ao longo do tempo buscaram a substituição do termo "sertão" na identificação de Goiás. Nesse estudo, o pesquisador faz um relato da nomenclatura que concorreu com a designação de sertão, que incluiu termos como "coração do Brasil", "Oeste", "Planalto Central" e "Cerrado".

Como é elencado pelo autor, essas investidas tiveram início no final do século XIX, quando foram evidenciados os termos "planalto" e "cerrado" na concorrência com "sertão". Houve uma tentativa de valorização das características morfológicas de Goiás, tendo como base o Planalto Central e a predominante vegetação de cerrado.

Nesse momento, a conjuntura brasileira tinha como centralidade a expansão cafeeira no Sudeste brasileiro, responsável pelo encaminhamento do capital em direção ao oeste, tendo como símbolo o adentramento da ferrovia pelo Triângulo Mineiro e pelo Sudoeste Goiano. Para muitos pesquisadores, notadamente Borges (2000), iniciou-se então o papel estratégico de Goiás na expansão capitalista pelo interior do Brasil. 
De acordo com Corbacho Quintela (2010), na altura de 1930 ocorreu uma nova investida na substituição do termo "sertão", pois naquele momento o termo "Oeste", vinculado à ideia de coração do Brasil, era a referência para identificar Goiás. No contexto de então, a política de governo Marcha para o Oeste comandava a busca de uma brasilidade, como destaca Souza (2015). Goiás foi então o lócus para essa conquista e, portanto, ponto de partida para a construção de uma nação pautada na superação do sertão (atraso) pela modernidade (Oeste). Tal momento foi considerado por muitos estudiosos, dentre os quais Campos (2003) e Estevam (2004), como o fim da ausência do Estado em relação a Goiás. Como já foi destacado, iniciava-se, assim, pela via das políticas públicas, uma intensa intervenção dos governos Vargas (1930-1945) e Juscelino Kubitschek (1955-1960) em solo goiano, respondendo às demandas da industrialização e da urbanização brasileiras.

No contínuo das investidas, Corbacho Quintela (2010) afirma que é o vocábulo "cerrado" que se consolida como substituto de "sertão" na identificação de Goiás. Essa tendência ocorreu na década de 1980, tendo como motivador o estudo publicado por Mauro Borges, em 1985, intitulado A conquista do Cerrado, que apresentou uma proposta para a duplicação da produção de grãos em Goiás. Nesse momento, o estado encontravase sob a lógica da produção intensificada do capital. A ação política no território goiano também foi fortalecida pelos governos militares por meio dos Planos Nacionais de Desenvolvimento (PND's) que, somados a outros períodos e eventos apontados por Castilho (2016), ampliaram e consolidaram a modernização territorial em Goiás.

Embora não seja especificado na pesquisa de Corbacho Quintela, o movimento de substituição do termo "sertão" para a identificação de Goiás esteve atrelado ao planejamento de expansão capitalista no interior do Brasil. O que corrobora essa afirmação é o fato de as propostas de substituição terem sido apresentadas em momentos conjunturais, cruciais para esse movimento expansionista. Nesse sentido, as referidas terminologias fizeram parte estratégica da ação ideológica do capital veiculada pelo Estado em sua expansão pelo território brasileiro. Nessa condição, o termo "cerrado" consolidou-se na década de 1980 como força representativa e de poder simbólico de uma conjuntura de modernização do campo em Goiás, haja vista o fato inspirador estar atrelado à proposta de crescimento da produção de grãos.

O fato a se destacar é que a modernização do campo em Goiás, consolidada pós- 1970, foi resultado de um conjunto de medidas para o avanço do capital no Brasil, iniciadas ainda no final do século XIX e estendidas até então. Foi com a modernização do campo e a reestruturação produtiva de Goiás que a estrutura sertão perdeu preeminência. O termo "cerrado" representou, então, a nova matriz espacial do território goiano.

O termo "sertão" esteve condicionado à ideia de atraso, condição que, na perspectiva de sua superação, necessariamente passaria pela nomenclatura. A proposta era superar o sertão em nome de um novo tempo que reorientaria a organização produtiva de Goiás e o integraria à lógica mundial da acumulação intensificada do capital. Goiás foi ponto estratégico para isso, por se constituir na porta de entrada para a expansão 
capitalista no interior do Brasil. O fator determinante foi a intensa intervenção do Estado em solo goiano a partir do início do século XX. No entanto, entende-se que, na década de 1970, Goiás deixou de ser sertão e passou a ser cerrado. Nesse momento, as variáveis externas suplantaram as variáveis internas, condicionando o cerrado como nova organização espacial de Goiás.

O Estado foi o ente que encaminhou essa transição, portanto responsável direto pela criação da imagem do cerrado e por sua propagação representada na ordem ambientalista. Por isso, reitera-se aqui a afirmação de Inocêncio (2012, p. 3): “o Cerrado foi obra pensada e articulada pelo Estado, na conjuntura nacional e internacional dos anos de 1970". A ação estatal já ocorria em tempos anteriores, no período preparatório da modernização do campo em Goiás. Tal período é gestado no imaginário territorial de Goiás a partir do final do século XIX e estende-se até a década de 1950. Uma vez que o Brasil rural sinalizava a noção de atraso, urbanizar significava elevar-se ao patamar do progresso dos países ricos: "Modernizar é o instrumento de fazer do território o palco do progresso. A política pública é o veículo concreto, financeiro, ideológico que põe máquinas, fios e políticas para desenvolver a aproximação entre os lugares e o mundo capitalista" (BORGES, 2007, p. 20).

A transição do sertão para o cerrado, ao transformar a estrutura espacial de Goiás, impôs condições reestruturadoras de base socioespacial, o que reverbera na existência do sertanejo goiano; este, a partir de então, foi inserido em uma nova condição existencial, ou seja, uma (re)existência. Segundo Almeida (2005, 2008), coloca-se em risco a cultura do sertanejo pela via do comprometimento de suas festas, modos de falar e culinária, bem como os modos de vida de povos indígenas e camponeses, dentre outros que entraram decisivamente no rol das interferências do novo modelo de organização territorial do Brasil que passou a comandar Goiás.

Para Calaça (2010), essa realidade foi consolidada com a modernização do campo em Goiás. A modernidade retirou do sertanejo sua base principal, a saber, a proximidade com a natureza e o acesso à terra, inteirando-o na dinâmica espacial do tempo rápido evidenciado no meio urbano, em que saberes, gostos e costumes contrastavam com a realidade de então. Nessa condição, o novo modelo, Goiás do cerrado, suprimiu o modo de vida sertanejo, acarretando a perda dos conhecimentos populares.

A modernidade e todas suas possíveis derivações têm sua materialidade que atinge o cotidiano da sociedade e modifica as relações sociais. As suas repercussões, a sua penetração nos múltiplos espaços do fazer político, social, econômico, dizem muito das relações de poder existentes. Efetivamente, é um processo contraditório, cria conflitos, destrói valores, inventa concepções de mundo e de vida. (BERMAN, 1986, p. 13).

Esse quadro não significou, todavia, a total substituição do conhecimento popular ou tradicional, mas sim sua apropriação, levando-o a integrar-se à aplicação da tecnologia, que constituía a lógica do agronegócio. Portanto, a condição explicitada por Calaça (2010) levou à exclusão do sertanejo, ao tolher-lhe a matriz espacial e inseri-lo nos moldes de produção do agronegócio. A produção em grande escala, as sementes 
geneticamente modificadas e o uso de insumos foram novidades que o tiraram não só da produção, mas também da sua existência tradicional.

Atenta-se ainda, aqui, para a afirmação de Mendonça $^{1}$ de que a cultura sertaneja não desapareceu com a modernização territorial de Goiás ou com a respectiva urbanização, como se fosse transmutada para a identidade de um meio urbano, de um progresso. Pelo contrário, o sertanejo foi reinventado, agora no âmbito urbano.

As pessoas que foram deslocadas do campo para a cidade e que tem a memória com a terra, a memória dessas relações solidárias, de companheirismo, de ajuda mútua, também de sofrimento pela luta da terra, pela existência ela se reinventa no urbano. Basta olhar a casa de alguém que veio do campo. As casas podem ser conhecidas pela disposição espacial, pelas varandas, pelo que compõe, pelas plantas, ou mesmo a presença de pequenos animais. As varandas amplas, espaçosas para receber os amigos para uma conversa, com uma pamonha, mané pelado, um pão de queijo. É a forma que a cultura sertaneja se apresenta na realidade atual. Para mim a cultura não é algo museificado, ela se transforma. Então esse jeito de ser, em que as pessoas são recebidas na cozinha, em grande parte, sobretudo com as pessoas mais próximas. Sempre em volta de uma mesa, com uma guloseima, com alguma coisa que chame atenção é parte desse universo reinventado. Não tem problema eu ter uma televisão LED de última geração, ou meu filho usar internet $3 \mathrm{G}$. Então quer dizer, essa cultura sertaneja vai se realizando com outras experiências culturais, mas dificilmente ela apaga a memória com a terra. (Mendonça, entrevista em 23 nov. 2013).

O que se coloca em questão é a ideia de tensão das práticas sociais levantada por Souza (2015), que nesta pesquisa considera-se estar relacionada à condição de conflitos existenciais, tendo em vista a rápida mudança estrutural de Goiás. Segundo Souza (2015), esse fato colocou em evidência conflitos e convivências de ordens sociais divergentes no que se refere às relações econômicas e culturais e às ressignificações do espaço, do modo de produção, das festas, das relações familiares, o que vem tensionando o uso do espaço no Goiás do cerrado.

Aproximando-se dessa ideia, do conflito das temporalidades na organização espacial do cerrado, emergem práticas sociais sertanejas tensionadas pelas práticas sociais de um Goiás urbano. Esta pesquisa, porém, afasta-se da ideia de resíduos, ou seja, as práticas sociais sertanejas não são aqui entendidas como resquícios de uma temporalidade passada. Resíduo remete a imobilidade, permanência, restos, diminuto insignificante em relação a uma prática social maior. Esse conceito compromete a força da (re)existência, a capacidade de reinvenção do sertanejo, como é proposto por Mendonça (2004). Por isso, aporta-se na ideia de uma tensão cultural, de uma simbiose entre o sertanejo de preceitos rurais e o ser vivente do cerrado, de predominância cultural urbana, compondo a ontologia do ser goiano atual.

Entende-se que o cerrado imprime a Goiás uma configuração híbrida, advinda de sua condição gestada pela ordem urbana e por preceitos liberais. Ao que parece, ao mesmo tempo que esse urbano se mistura ao sertanejo, ao rural, também determina uma

1. Entrevista concedida ao autor em 23 nov. 2013. 
nova existência, dada sua força sedutora de mercado atuando coercitiva e indutoramente nas gerações mais antigas e inexoravelmente nas gerações mais jovens.

A estrutura socioespacial é um dos fatores determinantes da sociabilidade do ser humano como indivíduo e sujeito. Uma vez que essa estrutura deixa de existir, a existência dos sujeitos ganha novos contornos. É o que ocorreu com o sertanejo goiano na passagem do sertão para o cerrado. No entanto, não está morto o sertanejo, mas sim a estrutura que o condicionou em sua existência, o que abre caminhos para a interferência de uma nova sociabilidade predominante que tensionou de forma veemente as gerações mais antigas e, com menos efetividade, as mais novas. Portanto, não se defende aqui o fim do sertanejo, mas sim da predominância das bases de sua reprodução, haja vista a não possibilidade de retorno ou de predomínio do sertão, que deixa de existir como modelo hegemônico a partir da modernização do campo em Goiás.

Acompanhando esse raciocínio, no Goiás do cerrado o sertanejo se faz presente na culinária, com a pamonha e o frango caipira com pequi; na cultura, com as folias de reis e as novenas em louvor aos santos, popularmente conhecidas como festas de roça; na solidariedade camponesa, com os mutirões na colheita da roça; na política e no poder, com o modelo coronelista de governar e a manutenção dos grandes fazendeiros no domínio político; na força e coragem pela luta da terra, representada nos vários movimentos de retorno ao campo. Tais condições não se apresentam nos moldes do sertão, pois foram delineadas segundo os ditames da predominância do modelo urbano na composição atual de Goiás; todavia, certificam a presença do sertanejo na atualidade.

Vale lembrar que o urbano modelou a organização espacial do cerrado, sendo ente revelador dessa realidade. Para Chaveiro (2013), uma rápida pesquisa nos dados oficiais que mostram a situação das cidades inseridas no cerrado sintetiza os efeitos do que se entende por urbanização acelerada; tal situação compõe a rápida e contínua transferência da população rural para os espaços urbanos. Goiás foi o estado que apresentou o maior índice de urbanização na atualidade: mais de $90 \%$ da população reside nas cidades, com uma concentração profunda na Região Metropolitana de Goiânia.

Essa urbanização acelerada gerou uma rede urbana concentrada e desigual, o que afeta as formas, os tamanhos e as relações das cidades e suas interações, assim como seus conteúdos. De acordo com dados do Instituto Brasileiro de Geografia e Estatística - IBGE (2010), as grandes cidades goianas atraíram mais habitantes em detrimento das pequenas cidades, compondo uma situação de atração e retração populacional e de problemas sociais.

Para Chaveiro (2013), o fato a destacar é que os fundamentos dessa situação residem na condição imposta pela modernização do território goiano pela via do modelo agroexportador. Em tal lógica, as grandes cidades têm como papel fundamental a organização de um terciário propício para abastecer as demandas dessa economia agrária moderna. Já as pequenas cidades têm como função apenas abastecer as relações em nível local. Por outro lado, é determinada às cidades médias a função de gerar uma "urbanização extensiva e mirada ao circuito econômico agrícola" (CHAVEIRO, 2013, p. 12). 
Nessa rede urbana, a maior gravidade recai sobre o aumento dos problemas sociais. As cidades pequenas estagnadas impõem aos moradores a necessidade de migração, principalmente aos mais jovens, que, sem perspectivas de mobilidade, buscam as cidades médias e principalmente Goiânia com a expectativa de "vencer na vida", mesmo porque o imaginário da cidade grande como lócus do "desenvolvimento" ainda exerce forte influência na população mais jovem de Goiás.

As cidades médias, na sua maioria, insufladas pelo agronegócio, também servem como atrativo populacional, principalmente pela oferta de empregos do setor agroindustrial. Exemplo mais evidente desse quadro é Rio Verde, que, segundo dados do IBGE (2010), é a nona cidade com até quinhentos mil habitantes que mais cresce no Brasil. Nos últimos anos, porém, tornou-se uma das mais violentas de Goiás. No mesmo quadro encontram-se atreladas outras cidades médias, como Jataí e Catalão, que se tornaram atrativos populacionais e testemunharam o aumento da violência nos últimos anos.

As grandes cidades, compondo basicamente a Região Metropolitana de Goiânia, crescem acima da média brasileira. Dados do censo de 2010 mostram que, nos anos 2000, a taxa geométrica de crescimento populacional foi de $2,23 \%$ ao ano na metrópole goiana, de $1,84 \%$ no estado de Goiás e de $1,17 \%$ na média nacional. Nessa mesma velocidade cresceram os problemas sociais, levando Goiânia a ocupar a $28^{\mathrm{a}}$ posição no ranking das cidades mais violentas do mundo, segundo dados da organização não governamental (ONG) mexicana Consejo Ciudadano para la Seguridad Pública y Justicia Penal (ORTEGA, 2014).

Esse breve quadro urbano de Goiás evidencia a nova matriz espacial dada pela modernização do campo desde a década de 1970. De lá para cá, o que se viu foi um vertiginoso crescimento urbano, deflagrado inicialmente pela violenta saída do homem do campo e depois por uma intensa migração interna e externa. Receita para o avanço do capital, essa realidade condicionou-se em sérios problemas sociais, com ênfase para o crescimento da violência. Portanto, a imobilidade do Goiás do sertão, além de mais democrática, ensina que o homem é da terra e a terra é do homem, isto é, o afastamento um do outro implica o cerceamento da vida, como mostra a dinâmica do Goiás do cerrado sob os moldes da urbanidade capitalista, que privatizou a terra e democratizou as mazelas urbanas ao impor o "desespero urbano" à grande parte da população.

\section{Considerações finais}

No trajeto de uma síntese é possível afirmar que a modernização territorial do Brasil, sob os preceitos da modernidade, atravessou Goiás pela via da modernização do campo, inserindo-o na dinâmica do capital internacional. Esse processo intensificouse no começo do século XX, período preparatório para a modernização do campo, e consolidou-se na década de 1970, acarretando a passagem do sertão para o cerrado.

O Goiás do sertão foi uma organização espacial que se deu na interação de elementos políticos, econômicos e culturais, sob os moldes da ruralidade, base existencial do sertanejo goiano. A partir da década de 1970 essa organização foi redimensionada 
segundo os moldes de um Goiás urbano, o que imprimiu outra dimensão organizacional, o cerrado, a qual encerrou a hegemonia do sertão mas colocou em cena a (re)existência do sertanejo. Com isso, a modernização do campo em Goiás constituiu-se na fronteira entre Goiás do sertão e Goiás do cerrado. Essa fronteira é entendida, na perspectiva de Santos (2002), "como o limite da diferencialidade".

$\mathrm{O}$ que se viu foi uma rápida urbanização atrelada à exclusão da população do campo, o que afetou profundamente a existência sertaneja. Passou-se da matriz rural que a sustentava para uma matriz urbana, colocando em tensão as práticas sociais dos sujeitos goianos. No cômputo dessa urbanização estão as mazelas sociais que assolaram grande maioria da população, subjugada ao modelo de exploração que lhe tirou a possibilidade de uma vida digna, levando-a ao "desespero urbano". Conta a seu favor os movimentos em prol do "direito à cidade", como a luta pela melhoria dos transportes e em defesa da escola pública, ocorridos em Goiânia nos últimos anos, enquadrando a cidade nos caminhos do que Harvey (2014) chama de "cidades rebeldes".

Por fim, cabe destacar a credibilidade do MST, que tem atuado fortemente em Goiás. De posse do quadro caótico criado pela modernização do campo, evidenciado no "desespero urbano", o movimento levanta a bandeira de retorno ao campo como forma de dignificar o homem ao lhe devolver a terra. É o complemento das lutas empunhadas pelo movimento em torno de Santa Dica, pelos trabalhadores do arrendo do município de Orizona, pelos camponeses de Trombas e Formoso, pelos guerrilheiros do Araguaia, que muito lutaram para impedir esse quadro. Resta-nos acreditar em sua reversão apoiando a luta atual do MST e lembrando Pablo Neruda (2001, p. 102): "se cada dia cai dentro de cada noite, há um poço onde a claridade está presa. Há que sentar na beira do poço da sombra e pescar a luz caída com paciência”.

\section{Referências}

ALMEIDA, Maria Geralda. Dilemas territóriais e identitários em sítios patrimonializados: os Kalunga de Goiás. In: PELÁ, Márcia; CASTILHO, Denis (Org.). Cerrados: perspectivas e olhares. Goiânia: Ed. Vieira, 2010. p. 113-131.

ALMEIDA, Maria Geralda. Diversidades paisagísticas e identidades territoriais e culturais no Brasil sertanejo. In: ALMEIDA, Maria Geralda; CHAVEIRO, Eguimar F.; BRAGA, Helaine C. (Org.). Geografia e cultura: os lugares da vida e a vida dos lugares. Goiânia: Ed. Vieira, 2008. p. 47-74.

ALMEIDA, Maria Geralda. Fronteiras, territórios e territorialidades. Revista da ANPEGE, Fortaleza, ano 2, n. 2, p. 103-114, 2005.

ARRAIS, Tadeu A. A produção do território goiano: economia, urbanização, metropolização. Goiânia: Ed. UFG, 2013.

BERMAN, Marshall. Tudo que é sólido desmancha no ar: a aventura da modernidade. Tradução de Carlos Felipe Moisés e Ana Maria L. Ioriatti. São Paulo: Companhia das Letras, 1986.

BORGES, Barsanufo G. Goiás nos quadros da economia nacional: 1930-1960. Goiânia: Ed. UFG, 2000. 
BORGES, Júlio César P. Estado e políticas públicas: trilhos, estradas, fios e genes da modernização do território goiano. 2007. 116 f. Dissertação (Mestrado em Geografia) - Instituto de Estudos Socioambientais, Universidade Federal de Goiás, Goiânia, 2007. CALAÇA, Manoel. Territorialização do capital: biotecnologia, biodiversidade e seus impactos no Cerrado. Ateliê Geográfico, Goiânia, v. 4, n. 1, p. 18-35, fev. 2010.

CAMPOS, Francisco I. O coronelismo em Goiás. Goiânia: Ed. UFG, 2003.

CAMPOS FILHO, Romualdo P. Um olhar geopolítico sobre a água no Cerrado: apontamentos para uma preocupação estratégica. In: PELÁ, Márcia; CASTILHO, Denis (Org.). Cerrados: perspectivas e olhares. Goiânia: Ed. Vieira, 2010. p. 93-112.

CASTILHO, Denis. Modernização territorial e redes técnicas em Goiás. Goiânia: UFG, 2016.

CASTILHO, Denis; CHAVEIRO, Eguimar F. Por uma análise territorial do Cerrado. In: PELÁ, Márcia; CASTILHO, Denis (Org.). Cerrados: perspectivas e olhares. Goiânia: Ed. Vieira, 2010. p. 35-51.

CHAVEIRO, Eguimar Felício; CASTILHO, Denis. Cerrado: patrimônio genético, cultural e simbólico. In: Revista Mirante, vol. 2, n.1. Pires do Rio - GO: UEG, 2007.

CHAVEIRO, Eguimar F. Goiânia reinventada. Goiânia: Ed. Vieira, 2013.

CHAVEIRO, Eguimar F. Traços, linhas e matrizes para a compreensão de um Goiás profundo. In: _ A captura do território goiano e a sua múltipla dimensão socioespacial. Goiânia: Ed. Modelo, 2005. p. 168-188.

CHAVEIRO, Eguimar F.; BARREIRA, Celene C. M. A. Cartografia de um pensamento de Cerrado. In: PELÁ, Márcia; CASTILHO, Denis (Org.). Cerrados: perspectivas e olhares. Goiânia: Ed. Vieira, 2010. p. 15-35.

CORBACHO QUINTELA, Antón. Do Sertão ao Cerrado do Planalto Central: uma questão de nomenclatura. Revista UFG, Goiânia, ano XII, n. 9, p. 242-247, dez. 2010.

CUNHA, Marcos Antônio C. Recursos hídricos no Cerrado. In: GOMES, Horieste (Org.). Universo do Cerrado. Goiânia: Ed. da UCG, 2008. v. 2.

ESTEVAM, Luís. O tempo da transformação: estrutura e dinâmica da formação econômica de Goiás. 2. ed. Goiânia: Ed. da UCG, 2004.

FERREIRA, Idelvone M. Paisagens do Cerrado: um estudo do subsistema de veredas. In: GOMES, Horieste (Org.). Universo do Cerrado. Goiânia: Ed. da UCG, 2008. v. 1. p. $79-164$.

GOMES, Horieste. A nova matriz espacial do território goiano. In: . Universo do Cerrado. Goiânia: Ed. da UCG, 2008. v. 2. p. 353-376.

HARVEY, David. Cidades rebeldes: do direito à cidade à revolução urbana. Tradução de Jeferson Camargo. São Paulo: Martins Fontes, 2014.

INOCÊNCIO, Maria Erlan. Geopolítica e redes de poder: uma proposta metodológica para as pesquisas de campo no cerrado brasileiro. In: ENCONTRO NACIONAL DE 
GEOGRAFIA AGRÁRIA, 21., 2012, Uberlândia. Anais... Uberlândia, 2012. Disponível em: <http://www.lagea.ig.ufu.br/xxlenga/anais_enga_2012/eixos/1129_1.pdf > . Acesso em: 12 de abril de 2017, 15 de maio 2015.

INSTITUTO BRASILEIRO DE GEOGRAFIA E ESTATÍSTICA (IBGE). Resultado dos dados preliminares do Censo 2010. Rio de Janeiro, 2010.

LIMA, Sélvia C. Povos indígena do Cerrado goiano: os Karajá de Aruanã. In: PELÁ, Márcia; CASTILHO, Denis (Org.). Cerrados: perspectivas e olhares. Goiânia: Ed. Vieira, 2010. p. 131-154.

MENDONÇA, Marcelo R. A urdidura do trabalho e do capital no Cerrado do Sudeste Goiano. 2004. 457 f. Tese (Doutorado em Geografia) - Faculdade de Ciências e Tecnologia, Universidade Estadual Paulista, Presidente Prudente, 2004.

NERUDA, Pablo. Canto geral. Tradução de Paulo Mendes Campos. São Paulo: Difusão Editorial, 1997.

ORTEGA, José A. Por tercer año consecutivo, San Pedro Sula es la ciudad más violenta del mundo. Seguridad, Justicia y Paz - Consejo Ciudadano para la Seguridad Pública y Justicia Penal A. C., 15 enero 2014. Disponível em: <https://www.seguridadjusticiaypaz. org.mx/sala-de-prensa/941-por-tercer-ano-consecutivo-san-pedro-sula-es-la-ciudadmas-violenta-del-mundo>. Acesso em: 05 de março, 2017. 15 de maio 2015

PELÁ, Márcia; MENDONÇA, Marcelo R. Cerrado goiano: encruzilhada de tempos e territórios em disputa. In: PELÁ, Márcia; CASTILHO, Denis (Org.). Cerrados: perspectivas e olhares. Goiânia: Ed. Vieira, 2010. p. 51-70.

SANTOS, Douglas. A reinvenção do espaço: diálogos em torno da construção do significado de uma categoria. São Paulo: Ed. Unesp, 2002.

SILVA, Elaine B.; ANJOS, Antonio F. O monitoramento do desmatamento e as ações de conservação do bioma Cerrado na primeira década do século XXI. In: PELÁ, Márcia; CASTILHO, Denis (Org.). Cerrados: perspectivas e olhares. Goiânia: Ed. Vieira, 2010. p. 71-92.

SILVA, Lorranne G. Construção do lugar: trajetórias dos Avá-Canoeiro no Cerrado do Norte Goiano. In: PELÁ, Márcia; CASTILHO, Denis (Org.). Cerrados: perspectivas e olhares. Goiânia: Ed. Vieira, 2010. p. 155-180.

SOUZA, Candice V. e. A pátria geográfica: sertão e litoral no pensamento social brasileiro. 2. ed. Goiânia: Ed. UFG, 2015.

TEIXEIRA NETO, Antônio. Pequena história da agropecuária goiana (o ouro acabou? Viva o boi!/o ouro se foi? Chegou o boi!). 2008. Disponível em: <https:// observatoriogeogoias.iesa.ufg.br/up/215/o/teixeira_neto_ant_nio_pequena_hist_ agropecu_ria.pdf $>$. Acesso em: 12,fevereiro, 2015 
Júlio CésAr Pereira Borges

Doutor e mestre em Geografia pelo Instituto de Estudos Socioambientais (IESA) da Universidade Federal de Goiás, especialista em História do Brasil pela Universidade Federal de Goiás - Câmpus Catalão, e graduado em Geografia pela Universidade Federal de Goiás - Câmpus Catalão. Atualmente é professor efetivo do curso de Geografia da Universidade Estadual de Goiás - Câmpus Pires do Rio, onde também atua como coordenador adjunto de pesquisa.

Endereço: Rua Augusto Monteiro de Godoi, nº 56, centro, CEP: 75200000.

E-mail: jcesar.ueg@gmail.com

Recebido para publicação em junho de 2016 Aprovado para publicação em dezembro de 2016 